\title{
Competition between an invasive urchin and commercially fished abalone: effect on body condition, reproduction and survivorship
}

\author{
Elisabeth M. A. Strain*, Craig R. Johnson \\ University of Tasmania, Department of Zoology, Private Bag 05, Hobart 7005, Australia
}

\begin{abstract}
Incursion of the urchin Centrostephanus rodgersii into Tasmania, Australia, and its establishment at high densities raises questions about its potential interactions with another large herbivore on subtidal rocky reefs, the commercially fished abalone Haliotis rubra. Surveys on the southeast coast of Australia show a negative relationship between densities of $C$. rodgersii and $H$. rubra at several spatial scales, suggesting negative interactions. In intact algal beds, we used enclosures to estimate the effects and relative magnitude of intra- and interspecific competition on the body condition, gonad development and survival of $C$. rodgersii and $H$. rubra. An increased density of conspecifics led to declines in the dry gonad weight of $C$. rodgersii and in the dry foot and stomach content weights of $H$. rubra. The effects of interspecific competition were asymmetrical. Manipulations of $H$. rubra densities had no detectable effect on $C$. rodgersii. In contrast, in enclosures with added $C$. rodgersii, $H$. rubra showed reduced total and dry weights of stomach contents and increased mortality relative to controls without urchins. The effects of $C$. rodgersii on $H$. rubra could be linked to differences in feeding habits and morphology. C. rodgersii is a generalist herbivore, which, even at low densities, reduced the cover and standing biomass of total, brown and red algae relative to controls without urchins. In contrast, $H$. rubra is a specialist herbivore, which, even at high densities, had little effect on the cover and standing biomass of algae relative to the effect of C. rodgersii. This study suggests that the invader $C$. rodgersii is the superior competitor in interactions with $H$. rubra, and that its presence, even at low densities, affects the abalone fishery.
\end{abstract}

KEY WORDS: Invasion · Fishing $\cdot$ Competition $\cdot$ Centrostephanus rodgersii $\cdot$ Haliotis rubra

\section{INTRODUCTION}

With invasions of marine ecosystems increasing worldwide, it is important to identify the mechanisms of successful invasions to better predict future invaders, and to provide insight into the dynamics of invaded systems (Carlton 1992). The nature of competitive interactions between non-indigenous and native species can be an important determinant of invasion success, and the establishment of many nonindigenous species has been linked to superior competitive ability (Carlton 1992). However, some non-indigenous species only become invasive when their competitors are removed, through either natural or human disturbances (Baltz \& Moyle 1993). While there is substantial evidence that interspecific competition for food and/or shelter can be a key factor in invasion success in terrestrial and freshwater ecosystems, relatively few examples exist for marine ecosystems (Baltz \& Moyle 1993, Byers 2000, Jensen et al. 2002).

The long-spined urchin Centrostephanus rodgersii has undergone a southerly range expansion from New South Wales, being first discovered in mainland Tasmania in 1978 (Edgar 1997). C. rodgersii and blacklip abalone Haliotis rubra co-occur in similar habitat, and share predators and some overlap in diet in intact algal beds. This urchin is well known for its 
ability to overgraze macroalgal beds, resulting in a shift to 'barrens' habitat (Johnson et al. 2005). C. rodgersii barrens are becoming more widespread along the east coast of Tasmania and do not support viable fisheries of $H$. rubra. Whereas much of the research on the impacts of $C$. rodgersii on $H$. rubra densities has focused on barrens habitat, the nature of interactions between these 2 herbivores in intact algal beds, before any commencement of destructive urchin grazing, is not well understood. Assessing the effects of interspecific competition between $C$. rodgersii and $H$. rubra in intact algal beds is important to understand the mechanism behind the successful establishment of this urchin and the eventual exclusion of the abalone.

Interactions between abalone and urchins are complex and differ substantially between ecosystems. In Japan, South Africa and California, some urchin and abalone abundances are positively correlated, because juvenile abalone shelter beneath the spine canopy of adult urchins (Day \& Branch 2000, RogersBennett \& Hearse 2001). In contrast, in Southeast Australia and New Zealand, abundances of the urchins Centrostephanus rodgersii (Andrew \& Underwood 1992, Johnson et al. 2005) and Evechinus chloroticus (Naylor \& Gerring 2001), respectively, are usually negatively correlated with Haliotis spp. at a range of spatial scales. Hypotheses to explain negative correlations between C. rodgersii and $H$. rubra include competition for food (Shepherd 1973) and shelter (Andrew et al. 1998), but neither idea has been critically tested. Despite this, several authors have suggested that competition for food is the dominant interaction between $C$. rodgersii and $H$. rubra, because urchins are generalist herbivores, while abalone are specialist herbivores (Andrew 1989, Shepherd 1973).

Separating the effects and estimating the relative magnitude of intra- and interspecific competition for food is important in assessing the effects of competition. If the interspecific effects are stronger than the intraspecific effects, the establishment of Centrostephanus rodgersii may have negative impacts on the abundance and distribution of Haliotis rubra, or fishing abalone could facilitate the establishment of the urchin. Intraspecific competition for food has been demonstrated among C. rodgersii in New South Wales (Blount 2004) and some Haliotis spp. in Victoria (Huchette et al. 2003), but the effects of interspecific competition for food between C. rodgersii and H. rubra have not been tested. We manipulated densities of $C$. rodgersii and $H$. rubra in enclosures to test the effects and relative magnitude of intra- and interspecific competition for food on their body condition, gonad development and survival.

\section{MATERIALS AND METHODS}

Site characteristics. The experiment was conducted on subtidal rocky reefs at North Bay $\left(42.52^{\circ} \mathrm{S}\right.$, $147.47^{\circ} \mathrm{E}$ ), on the east coast of Tasmania, Australia, between February and August 2006. This site is characterised by gently sloping substratum reaching a depth of 15 to $17 \mathrm{~m}$, with moderate topographic relief. Using the classification system proposed by Edgar (1984), it is described as moderately sheltered. North Bay is exposed to south-easterly swells, which, although infrequent, can be large. Reefs support a variety of habitat from small urchin barren patches (dominated by Centrostephanus rodgersii and without foliose algae) to areas dominated by diverse stands of canopy-forming algae, with a well-developed understorey.

The abundance, distribution and mean size of Centrostephanus rodgersii and Haliotis rubra were estimated from twenty randomly positioned $3 \times 3 \mathrm{~m}$ quadrats between depths of 3 and $17 \mathrm{~m}$. The mean abundance and size of $C$. rodgersii was 10 ind. per $9 \mathrm{~m}^{2}$ $( \pm 2 \mathrm{SE})$; the mean test diameter was $107.6 \mathrm{~mm}( \pm 8.1$ $\mathrm{mm} \mathrm{SE}$ ). The mean abundance and size of $H$. rubra was 10 ind. per $9 \mathrm{~m}^{2}( \pm 5 \mathrm{SE})$; the mean shell length was $119.67 \mathrm{~mm}( \pm 3.3 \mathrm{~mm} \mathrm{SE})$. Animals were measured using vernier callipers.

Experimental design. We manipulated densities of Centrostephanus rodgersii and Haliotis rubra in enclosures to assess the effects and relative magnitude of intra- and interspecific competition at different densities. Enclosures were made of nylon netting $(3 \times 3 \times$ $1.5 \mathrm{~m}$ ), with a mesh size of $50 \mathrm{~mm}$, and were fully enclosed. Two rows of chain lined the bottom of the mesh, securing it to the bottom and preventing animal immigration and emigration. Enclosures were placed haphazardly $\sim 10 \mathrm{~m}$ apart at depths of 10 to $12 \mathrm{~m}$ on intact algal reef where $C$. rodgersii and $H$. rubra co-occurred. All pre-existing $C$. rodgersii and $H$. rubra were removed. Initial assessments of the cover of different substratum types (large boulders $>1$ to $<2.5 \mathrm{~m}$ diameter, mean $\pm \mathrm{SE}=26.11 \pm 3.86 \%$; small boulders $>0.2$ to $<1 \mathrm{~m}$ diameter, mean $\pm \mathrm{SE}=66.85 \pm 4.48 \%$; and sand, mean $\pm \mathrm{SE}=7.04 \pm 1.29 \%$ ), cover of algal divisions (brown, green and red algae, mean $\pm \mathrm{SE}=75.93 \pm$ $2.07 \%, 14.08 \pm 0.94 \%$ and $2.22 \pm 0.79 \%$, respectively) and density of benthic invertebrates (urchins, mean \pm $\mathrm{SE}=0.56 \pm 0.24$ per $9 \mathrm{~m}^{2} ;$ gastropods, mean $\pm \mathrm{SE}=$ $1.82 \pm 1.79$ per $9 \mathrm{~m}^{2}$; and cover of sessile invertebrates, mean $\pm \mathrm{SE}=2.78 \pm 3.76 \%$ ) were made by eye

Tagging Centrostephanus rodgersii and Haliotis rubra. C. rodgersii and $H$. rubra were collected from North Bay and tagged on the diving vessel. Abalone shells were scrubbed with a copper-wire bush, and hall print FPN (flexible polyethylene) tags $(8 \times 4 \mathrm{~mm})$ 
were glued to the shell using Loctite 454. Urchins were tagged using a modification of the methods by Pederson \& Johnson (2006). Two holes were made in the test using a $1.25 \mathrm{~mm}$ diameter hypodermic needle. The needle passed through the test between the oral and aboral surface. Monofilament fishing line $(0.5 \mathrm{~mm}$ diameter) was threaded through the needle, which was then removed. Colour-coded beads were threaded over the line in individual combinations, which was closed as a loop with a number 4 size Leader sleeve. Tagged C. rodgersii (test diameters from 104 to $116 \mathrm{~mm}$ and a measurement error mean $\pm \mathrm{SE}=1.89 \pm$ $0.04 \mathrm{~mm}$ ) and $H$. rubra (shell lengths from 114 to $126 \mathrm{~mm}$ ) were allocated randomly to enclosures. Animals that died within $24 \mathrm{~h}$ after initiating treatments were replaced (3.92\% abalone, $10.1 \%$ urchin).

Treatments. Treatments enabling tests of intraspecific competition (Tables $1 \& 2$ ) were $1 \times$ and $2 \times$ the ambient density of Centrostephanus rodgersii (1U0A vs. 2U0A) and Haliotis rubra (0U1A vs. 0U2A), respectively. Treatments enabling comparisons of interspecific competition (Tables $1 \& 2$ ) were $1 \times$ the ambient density of $C$. rodgersii with $1 \times$ the ambient density of H. rubra (1U1A), $1 \times$ the ambient density of $C$. rodgersii

Table 1. Centrostephanus rodgersii and Haliotis rubra. Treatments involving manipulations of $C$. rodgersii (U) and $H$. rubra (A) densities in $9 \mathrm{~m}^{2}$ enclosures. Ambient densities of $C$. rodgersii (1U0A) and $H$. rubra (0U1A) were 10 animals per $9 \mathrm{~m}^{2}$. All treatments were multiples of these densities

\begin{tabular}{|lcccccccc|}
\hline Treatments & 1 & 2 & 3 & 4 & 5 & 6 & 7 & 8 \\
& 1U0A & 2U0A & 1U1A & 1U2A & 2U1A & 2U2A & 0U1A & 0U2A \\
\hline C. rodgersii & 10 & 20 & 10 & 10 & 20 & 20 & 0 & 0 \\
H. rubra & 0 & 0 & 10 & 20 & 10 & 20 & 10 & 20 \\
H. rubra + & 10 & 20 & 20 & 30 & 30 & 40 & 10 & 20 \\
C. rodgersii & & & & & & & & \\
\hline
\end{tabular}

with $2 \times$ the ambient density of $H$. rubra (1U2A), $2 \times$ the ambient density $C$. rodgersii with $1 \times$ the ambient density of $H$. rubra (2U1A), and $2 \times$ the ambient density of C. rodgersii with $2 \times$ the ambient density of $H$. rubra (2U2A); $1 \times$ the ambient (average density at North Bay) and $2 \times$ the ambient (the maximum density at North Bay). $1 \times$ and $2 \times$ the ambient densities of $H$. rubra and C. rodgersii were 10 and 20 ind. per $9 \mathrm{~m}^{2}$, respectively. Enclosures were checked monthly and cleaned of accumulated algae and sediment. The identity of living $C$. odgersii and $H$. rubra were recorded, and dead animals were removed. To test for the effect of enclosures on $C$. rodgersii and $H$. rubra, tagged animals were placed outside enclosures $(n=3)$, at $1 \times$ the ambient density (1U0A and 0U1A). All pre-existing C. rodgersii and $H$. rubra were removed from control areas. Urchins and abalone did not reinvade these areas. The experiment was maintained for $6 \mathrm{mo}$, at which time all animals were collected.

Response variables. To assess body size increments, animals were returned to the laboratory and remeasured using vernier callipers, and these values were compared with initial measurements. Total wet weight was then recorded for each animal.

Animals were sexed, and their gonad development was assessed. To induce spawning in Centrostephanus rodgersii, specimens were injected with $5 \mathrm{ml}$ of $0.05 \mu \mathrm{mol} \mathrm{KCl}$, and spawn (presence, absence) and sex (males, female) were recorded. C. rodgersii were dissected, and their major body components (gonad, lantern, test and spines and stomach contents) were separated and dried for $3 \mathrm{~d}$ at $60^{\circ} \mathrm{C}$ before weighing.

Table 2. Centrostephanus rodgersii and Haliotis rubra. Details of comparisons to test for intra- and interspecific competition on C. rodgersii $(\mathrm{U})$ and $H$. rubra $(\mathrm{A})$, and effects of species on the cover and standing biomass of algae. Ambient densities of $C$. rodgersii (1U0A) and H. rubra (0U1A) were 10 animals per $9 \mathrm{~m}^{2}$. All treatments were multiples of these densities. For the interspecific competition contrasts, treatments were pooled and linear coefficients recalculated

\begin{tabular}{|c|c|c|c|}
\hline Intra- vs. interspecific & Intraspecific & Effect of abalone and urchin densities & Cover, standing biomass algae \\
\hline $\begin{array}{l}\text { A: } 2 \mathrm{U} 0 \mathrm{~A} \text { vs. } 1 \mathrm{U} 1 \mathrm{~A}: \text { effect } \\
\text { of } 2 \mathrm{U} \text { relative to } 1 \mathrm{~A}\end{array}$ & $\begin{array}{l}\text { E: } 1 \text { UOA vs. } 2 U 0 A: \\
\text { effect of } 2 \mathrm{U}\end{array}$ & $\begin{array}{c}\text { G: } 1 \mathrm{U} 0 \mathrm{~A}, 2 \mathrm{U} 0 \mathrm{~A} \text { vs. } 1 \mathrm{U} 1 \mathrm{~A}, 2 \mathrm{U} 1 \mathrm{~A}: \\
\text { effect of } 1 \mathrm{~A}\end{array}$ & $\begin{array}{l}\text { M: 0U1A, 0U2A vs. 1U0A,1U1A, 1U2A: } \\
\text { effect of } 1 \mathrm{U}\end{array}$ \\
\hline $\begin{array}{l}\text { B: } 1 \mathrm{U} 2 \mathrm{~A} \text { vs. } 2 \mathrm{U} 1 \mathrm{~A}: \text { effect } \\
\text { of } 1 \mathrm{~A} \text { relative to } 2 \mathrm{~A}\end{array}$ & & $\begin{array}{l}\text { H: } 1 \mathrm{U} 0 \mathrm{~A}, 2 \mathrm{U} 0 \mathrm{~A} \text { vs. } 1 \mathrm{U} 2 \mathrm{~A}, 2 \mathrm{U} 2 \mathrm{~A}: \\
\text { effect of } 2 \mathrm{~A} \\
\text { I: } 1 \mathrm{U} 1 \mathrm{~A}, 2 \mathrm{U} 1 \mathrm{~A} \text { vs. } 1 \mathrm{U} 2 \mathrm{~A}, 2 \mathrm{U} 2 \mathrm{~A}: \\
\text { effect of } 1 \mathrm{~A} \text { relative to } 2 \mathrm{~A}\end{array}$ & $\begin{array}{l}\text { N: 0U1A, } 0 \mathrm{U} 2 \mathrm{~A} \text { vs. } 2 \mathrm{U} 0 \mathrm{~A}, 2 \mathrm{U} 1 \mathrm{~A}, 2 \mathrm{U} 2 \mathrm{~A} \text { : } \\
\text { effect of } 2 \mathrm{U} \\
\text { O: } 1 \mathrm{U} 0 \mathrm{~A}, 1 \mathrm{U} 1 \mathrm{~A}, 1 \mathrm{U} 2 \mathrm{~A} \text { vs. } 2 \mathrm{U} 0 \mathrm{~A}, 2 \mathrm{U} 1 \mathrm{~A}, 2 \mathrm{U} 2 \mathrm{~A} \text { : } \\
\text { effect of } 1 \mathrm{U} \text { relative to } 2 \mathrm{U}\end{array}$ \\
\hline $\begin{array}{l}\text { C: } 0 \mathrm{U} 2 \mathrm{~A} \text { vs. } 1 \mathrm{U} 1 \mathrm{~A} \text { : effect } \\
\text { of } 2 \mathrm{~A} \text { relative to } 1 \mathrm{U}\end{array}$ & $\begin{array}{l}\text { F: 0U1A vs. 0U2A: } \\
\text { effect of 2A }\end{array}$ & $\begin{array}{l}\text { J: 0U1A, 0U2A vs. } 1 \mathrm{U} 1 \mathrm{~A}, 1 \mathrm{U} 2 \mathrm{~A}: \\
\text { effect of } 1 \mathrm{U}\end{array}$ & $\begin{array}{l}\text { P: 1U0A, 2U0A vs. 0U1A,1U1A, 2U1A: } \\
\text { effect of } 1 \mathrm{~A}\end{array}$ \\
\hline $\begin{array}{l}\mathrm{D}: 1 \mathrm{U} 2 \mathrm{~A} \text { vs. } 2 \mathrm{U} 1 \mathrm{~A} \text { : effect } \\
\text { of } 1 \mathrm{U} \text { relative to } 2 \mathrm{U}\end{array}$ & & $\begin{array}{l}\text { K: } 0 \mathrm{U} 1 \mathrm{~A}, 0 \mathrm{U} 2 \mathrm{~A} \text { vs. } 2 \mathrm{U} 1 \mathrm{~A}, 2 \mathrm{U} 2 \mathrm{~A}: \\
\text { effect of } 2 \mathrm{U} \\
\text { L: } 1 \mathrm{U} 1 \mathrm{~A}, 1 \mathrm{U} 2 \mathrm{~A} \text { vs. } 2 \mathrm{U} 1 \mathrm{~A}, 2 \mathrm{U} 2 \mathrm{~A}: \\
\text { effect of } 1 \mathrm{U} \text { relative to } 2 \mathrm{U}\end{array}$ & $\begin{array}{l}\text { Q: } 1 \mathrm{U} 0 \mathrm{~A}, 2 \mathrm{U} 0 \mathrm{~A} \text { vs. } 0 \mathrm{U} 2 \mathrm{~A}, 1 \mathrm{U} 2 \mathrm{~A}, 2 \mathrm{U} 2 \mathrm{~A}: \\
\text { effect of } 2 \mathrm{~A} \\
\text { R: 0U1A,1U1A,2U1A vs. 0U2A, 1U2A, 2U2A: } \\
\text { effect of } 1 \mathrm{~A} \text { relative to } 2 \mathrm{~A}\end{array}$ \\
\hline
\end{tabular}


Haliotis rubra were dissected, and their maturity (mature, immature) and sex (male, female) were determined by visual inspection of the gonad. If the testis or ovary could be discerned, they were considered to be sexually mature. The maturity and sex of abalone that were infected with trematode cercariae $(6 \%)$ could not be determined, and those individuals were excluded from this component of the analysis. Major body components of $H$. rubra (gonad, foot, shell, stomach contents) were separated, dried and weighed.

To determine the effects of Centrostephanus rodgersii and Haliotis rubra grazing on the abundance of attached algae in enclosures, the percentage cover of algal divisions (brown, red) was estimated by eye in situ at the conclusion of the experiment. A similar assessment was also made in the control areas. All algae were then collected by hand, bagged, returned to the laboratory and dried for $3 \mathrm{~d}$ at $60^{\circ} \mathrm{C}$ before weighing. Throughout the experiment, drift algae were also found both inside enclosures and in control areas, but because of high spatial and temporal variability in the abundance and condition of this resource, it was not collected.

Analysis. The effects of enclosures on increments (final - initial) of Centrostephanus rodgersii test width and Haliotis rubra shell length were analysed with 1way ANOVA (main effect enclosures, fixed, 2 levels = present, absent). The effects of enclosures on the total wet weight and dry weights of body components of $C$. rodgersii and $H$. rubra were analysed with 1-way ANCOVA (main effect enclosures, fixed, 2 levels = present, absent, covariate $=$ initial test width, shell length).

The impacts of enclosures on the gonad development of Centrostephanus rodgersii and Haliotis rubra (proportion of mature, spawning animals) were analysed using logistic modelling (see above details). In this analysis, generalized linear models were used, assuming a binomially distributed response variable (maturity = mature, immature) using a logit function. Where significant differences were found, odds ratios and confidence intervals were calculated. We used the log-likelihood ratio test to assess the fit of the model.

The effects of intra- and interspecific competition on the increments of Centrostephanus rodgersii test width and Haliotis rubra shell length were analysed with 2way ANOVA. To examine effects on C. rodgersii, the model included the main effects of urchins (fixed, 2 levels $=1 \mathrm{U}, 2 \mathrm{U}$ ), abalone (fixed, 3 levels $=0 \mathrm{~A}, 1 \mathrm{~A}$ and 2A) and their interaction. Similarly, for H. rubra, the model included the main effects of abalone (fixed, 2 levels $=1 \mathrm{~A}, 2 \mathrm{~A}$ ) and $C$. rodgersii $($ fixed, 3 levels $=0 \mathrm{U}$, $1 \mathrm{U}$ and $2 \mathrm{U})$, and their interaction.
The effects of intra- and interspecific competition on Centrostephanus rodgersii and Haliotis rubra weights were analysed with 2-way ANCOVA. The models included the main effects of urchin, abalone, the covariate and their interactions (see above details). To examine the effects on urchin and abalone dry gonad weight the models also included the main effect of sex (fixed, 2 levels = male, female).

The effects of intra- and interspecific competition on Centrostephanus rodgersii and Haliotis rubra gonad development were analysed using logistic modelling. Models included the main effects of $C$. rodgersii, $H$. rubra, the covariate and their interactions (see above details).

The effects of intra- and interspecific competition on Centrostephanus rodgersii and Haliotis rubra survivorship were analysed using the Cox proportional hazards regression model ('Survival' in R). For this analysis, animals whose remains could not be found and that did not die at the conclusion of the experiment were treated as censored observations. Models included the main effects of $C$. rodgersii, $H$. rubra, the covariate and their interactions (see above details). We used the Cox.zph function to test the proportional hazards assumption.

The effect of enclosures on the cover and standing biomass of the algal divisions was analysed with 1way ANOVA (main effect enclosures, fixed, 2 levels = present, absent). The effect of Centrostephanus rodgersii and Haliotis rubra in the different treatments on the cover and biomass of the algal divisions was analysed with an incomplete 2-way ANOVA. The model included the main effects of species (fixed, 2 levels = C. rodgersii, H. rubra) and density (fixed, 3 levels $=0 \mathrm{U}, 1 \mathrm{U}, 2 \mathrm{U}$ and $0 \mathrm{~A}, 1 \mathrm{~A}, 2 \mathrm{~A}$ ), and their interaction.

Throughout the present study, ANCOVA was used to adjust for initial body size. For all parametric analyses, the relationship between standard deviation and means of treatment groups was used to determine the appropriate transformation to stabilise variances, and transformed data were checked for both normality (using normal probability plots) and homoscedasticity. For ANCOVAs, we also tested for homogeneity of slopes as the interaction between the covariate and the main effects. Where homogeneity of slopes was indicated, we presented the reduced models. Transformations are expressed in terms of the raw dependent variable, $Y$. Where significant differences were evident in the overall tests, planned comparisons between treatments were made (see Tables 1 \& 2). Where comparison sets were non-orthogonal, the significance level was adjusted using the method by Todd \& Keough (1994). All statistical analysis and graphics were undertaken using $\mathrm{R}$. 


\section{RESULTS}

\section{Effect of enclosures on growth and gonad development}

Very few tagged Centrostephanus rodgersii $(\mathrm{n}=8)$ and Haliotis rubra $(\mathrm{n}=6)$ were recovered from outside the enclosures and so these animals were pooled for analysis using unbalanced $t$-tests. There were no detectable effects of enclosures on increments of $C$. rodgersii test width $(p=0.9)$, total weight $(p=0.79)$, or dry weights of gonad $(p=0.51)$, lantern $(p=0.58)$, stomach contents $(p=0.78)$, or spines and test $(p=0.57)$. Similarly, there was no detectable effect of enclosures on increments of $H$. rubra shell length $(p=0.3)$, total weight $(p=0.75)$, or dry weights of gonad $(p=0.5)$, foot $(p=0.78)$, shell $(p=$ $0.6)$, or stomach contents $(p=0.77)$. To check whether growth responses were independent of size, the body size increments of $C$. rodgersii and $H$. rubra were plotted against their total weight and dry body component weights. No significant relationships were evident.

The effect of enclosures on the gonad development of Centrostephanus rodgersii and Haliotis rubra were analysed with a row $\times$ column test of independence, using G-tests. To compensate for increased Type I error and low numbers, William's correction $(q)$ was used. There were no detectable effects of enclosures on the proportion of $C$. rodgersii that spawned $(\mathrm{p}=0.88)$ or the proportion of mature H. rubra $(\mathrm{p}=$ $0.72)$.

\section{Effect of competition on body size increments}

There was no evidence that intra- and interspecific competition affected increments in Centrostephanus rodgersii test width $\left(C\right.$. rodgersii, $F_{1,155}=0.1, p=0.93$; Haliotis rubra, $F_{2,155}=0.61, p=0.26 ; C$. rodgersii $\times$ $H$. rubra, $F_{2,155}=0.18, \mathrm{p}=0.84$ ) or increments in $H$. rubra shell length $\left(H\right.$. rubra, $F_{1,155}=1.32, \mathrm{p}=0.9$; C. rodgersii, $F_{2,155}=0.08, p=0.99 ; C$. rodgersii $\times$ H. rubra, $F_{2,155}=1.21, \mathrm{p}=0.12$ ).

\section{Effect of competition on total body and body component weights}

There were significant effects of intra- and interspecific competition on Centrostephanus rodgersii and Haliotis rubra (Figs. $1 \& 2$, Table 3 ). The nature of the effects and relative magnitude of intra- and interspecific competition on C. rodgersii and $H$. rubra varied according to the body components measured.
Increases in the density of conspecifics negatively influenced the body component weights of Centrostephanus rodgersii and Haliotis rubra. Average dry gonad weight was reduced by $40 \%$ when densities of C. rodgersii doubled. However, manipulations of C. rodgersii densities had no detectable effects on total wet weight or dry weights of lanterns, stomach contents, or test and spines. For H. rubra, increases in the density of conspecifics led to reduced dry weights of foot and stomach contents. When densities of $H$. rubra were doubled, average dry foot weight was reduced by $8 \%$, and the dry weight of stomach contents was reduced by $22.6 \%$. However, manipulations of abalone densities had no detectable effects on $H$. rubra total weight or the dry weights of gonad and shell.

Manipulations of Haliotis rubra densities had no detectable effects on Centrostephanus rodgersii total weight or the dry weights of urchin gonad, lantern, stomach contents, or test and spines. In contrast, inclusion of $C$. rodgersii in the enclosures at both ambient and double ambient densities resulted in significant but similar reductions in $H$. rubra total weight and dry weights of stomach contents relative to controls without urchins. The effects of $C$. rodgersii on dry gonad weight of $H$. rubra were only significant at double ambient densities when compared to controls without urchins. There were no detectable effects of $C$. rodgersii on the dry shell weight of $H$. rubra.

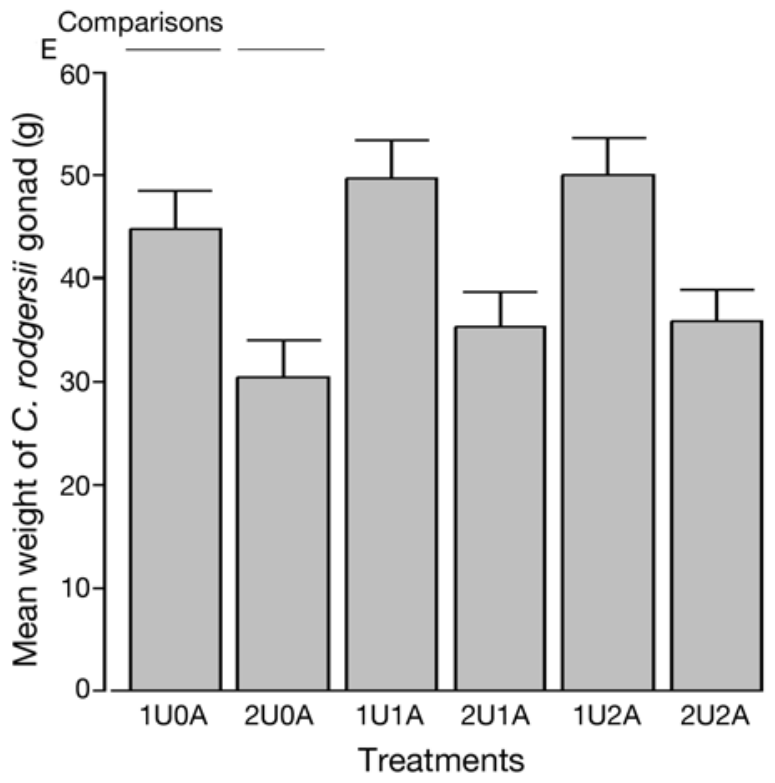

Fig. 1. Centrostephanus rodgersii and Haliotis rubra. Effects of intra- and interspecific competition on mean gonad dry weight $(\mathrm{g})$ (see Table 3$)$. Data are means $( \pm \mathrm{SE})$ of $\mathrm{n}=3$. $1 \mathrm{U}$ and $2 \mathrm{U}$ : $1 \times$ and $2 \times$ ambient density $C$. rodgersii; $0 \mathrm{~A}, 1 \mathrm{~A}$ and 2A: $0 \times, 1 \times$ and $2 \times$ ambient density $H$. rubra. Comparison is $\mathrm{E}$ : $1 \mathrm{U} 0 A$ versus $2 \mathrm{U} 0 A$. Single lines above indicate significant differences between treatment means 

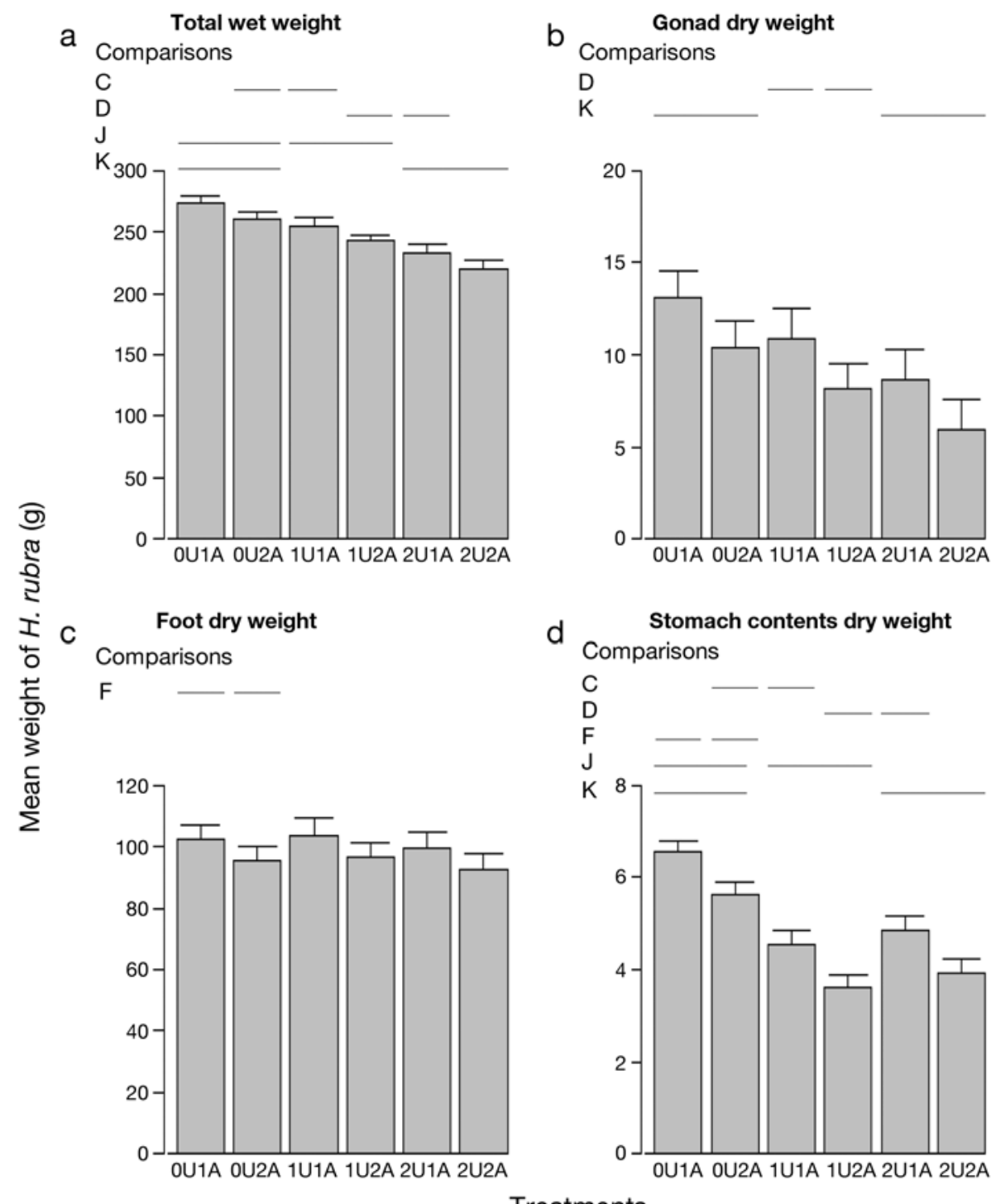

Fig. 2. Centrostephanus rodgersii and Haliotis rubra. Effects of intra- and interspecific competition on (a) mean total wet weight, and dry weights $(\mathrm{g})$ of $(\mathrm{b})$ gonad, (c) foot and (d) stomach content (see Table 3 ). Data are means $( \pm \mathrm{SE})$ of $\mathrm{n}=3.0 \mathrm{U}, 1 \mathrm{U}$ and $2 \mathrm{U}$ : $0 \times, 1 \times$ and $2 \times$ ambient density $C$. rodgersii; $1 \mathrm{~A}$ and $2 \mathrm{~A}$ : $1 \times$ and $2 \times$ ambient density $H$. rubra. Comparisons are $-\mathrm{C}$ : $0 \mathrm{U} 2 \mathrm{~A}$ versus $1 \mathrm{U} 1 \mathrm{~A} ; \mathrm{D}$ : 1U2A versus 2U1A; F: 0U1A versus 0U2A; J: 0U1A, 0U2A versus 1U1A, 1A2U; K: 0U1A, 0U2A versus 2U1A, 2U2A. Single lines above indicate significant differences between treatment means, and connecting lines indicate significant differences between groups of treatment means

Table 3. Centrostephanus rodgersii and Haliotis rubra. Results of ANCOVA testing effects of intra- and interspecific competition on growth of $C$. rodgersii expressed as total wet body weight and dry weight of body components (g). Significant p-values are in bold print: $p<0.05$ values are significant for the main analysis and $p<0.01$ values are significant for comparisons $(\alpha$-adjusted using the method by Todd \& Keough 1994)

\begin{tabular}{|lccccccc|}
\hline Source of variation & df & MS & $F$ & $p$ & Comparisons & F & Effect size \\
\hline C. rodgersii & & & & & & \\
Total wet weight $[\log (\boldsymbol{y}+\mathbf{0 . 0 0 1})]$ & & & & & \\
C. rodgersii & 1 & 0.01 & 0.28 & 0.59 & \\
H. rubra & 2 & 0.17 & 4.88 & 0.1 & \\
C. rodgersii $\times$ H. rubra & 2 & 0.04 & 1 & 0.38 & \\
\hline
\end{tabular}


Table 3 (continued)

\begin{tabular}{|c|c|c|c|c|c|c|c|c|}
\hline Source of variation & df & MS & $F$ & $\mathrm{p}$ & Comparisons & $F$ & $\mathrm{p}$ & Effect size \\
\hline Initial test width (covariate) & 1 & 2.49 & 71.29 & $1 e-14$ & & & & \\
\hline Residual & 159 & & & & & & & \\
\hline \multicolumn{9}{|l|}{ Gonad dry weight } \\
\hline C. rodgersii & 1 & 7439 & 15.45 & $1 e-04$ & 1U0A vs. 2U0A & 13.213 & $1 e-04$ & -20.81 \\
\hline H. rubra & 2 & 803 & 1.67 & 0.2 & & & & \\
\hline C. rodgersii $\times H$. rubra & 2 & 1011 & 2.1 & 0.13 & & & & \\
\hline Sex & 1 & 1092 & 2.59 & 0.11 & & & & \\
\hline Initial test width (covariate) & 1 & 2563 & 5.32 & 0.02 & & & & \\
\hline Residual & 125 & 1011 & & & & & & \\
\hline \multicolumn{9}{|c|}{ Lantern dry weight $[\log (y+0.0001)]$} \\
\hline C. rodgersii & 1 & 0.05 & 0.09 & 0.09 & & & & \\
\hline H. rubra & 2 & 0.01 & 0.47 & 0.63 & & & & \\
\hline C. rodgersii $\times H$. rubra & 2 & 0.01 & 0.17 & 0.85 & & & & \\
\hline Initial test width (covariate) & 1 & 0.74 & 53.4 & $1 e-11$ & & & & \\
\hline Residual & 159 & 0.02 & & & & & & \\
\hline \multicolumn{9}{|c|}{ Stomach content dry weight $[\log (y+0.001)]$} \\
\hline C. rodgersii & 1 & 0.09 & 0.66 & 0.42 & & & & \\
\hline H. rubra & 2 & 0.06 & 0.34 & 0.72 & & & & \\
\hline C. rodgersii $\times$ H. rubra & 2 & 0.12 & 1.14 & 0.33 & & & & \\
\hline Initial test width (covariate) & 1 & 0.11 & 1.8 & 0.18 & & & & \\
\hline Residual & 159 & & & & & & & \\
\hline \multicolumn{9}{|l|}{ Test and spines dry weight } \\
\hline C. rodgersii & 1 & 0.14 & 0.7 & 0.4 & & & & \\
\hline H. rubra & 2 & 0.08 & 1.31 & 0.28 & & & & \\
\hline C. rodgersii $\times H$. rubra & 2 & 0.21 & 1.15 & 0.32 & & & & \\
\hline Initial test width (covariate) & 1 & 0.28 & 98.28 & $<2 \mathrm{e}-16$ & & & & \\
\hline Residual & 159 & 0.21 & & & & & & \\
\hline \multicolumn{9}{|l|}{ H. rubra } \\
\hline Total wet weight $[\log (y+0.001)]$ & & & & & 0U2A vs. 1U1A & 10.86 & 0.01 & -17.33 \\
\hline C. rodgersii & 2 & 16090 & 20.22 & $6 e-08$ & $1 \mathrm{U} 2 \mathrm{~A}$ vs. $2 \mathrm{U} 1 \mathrm{~A}$ & 10.11 & 0.01 & -16.9 \\
\hline H. rubra & 1 & 805 & 1.01 & 0.32 & 0U1A, 0U2A vs. 1U1A,1U2A & 10.36 & $2 e-03$ & -20.97 \\
\hline C. rodgersii $\times H$. rubra & 2 & 20366 & 2.45 & 0.1 & 0U1A, 0U2A vs. 2U1A, 2U2A & 30.42 & $7 e-07$ & -42.48 \\
\hline Initial shell length (covariate) & 1 & 1947 & 25.6 & $3 e-06$ & $1 \mathrm{U} 1 \mathrm{~A}, 1 \mathrm{U} 2 \mathrm{~A}$ vs. $2 \mathrm{U} 1 \mathrm{~A}, 2 \mathrm{U} 1 \mathrm{~A}$ & 4.42 & 0.03 & -19.79 \\
\hline Residual & 89 & 796 & & & & & & \\
\hline \multicolumn{5}{|l|}{ Gonad dry weight $[\log (y+0.0001)]$} & 0U2A vs. 1U1A & 4.71 & 0.04 & -2.26 \\
\hline C. rodgersii & 2 & 0.83 & 13.61 & $1 e-05$ & $1 \mathrm{U} 2 \mathrm{~A}$ vs. $2 \mathrm{U} 1 \mathrm{~A}$ & 1.64 & 0.18 & 5.56 \\
\hline H. rubra & 1 & 0.02 & 0.3 & 0.6 & 0U1A vs. 0U2A & 2.84 & 0.11 & -8.3 \\
\hline C. rodgersii $\times H$. rubra & 2 & 0.29 & 4.82 & 0.02 & 0U1A, 0U2A vs. 1U1A,1U2A & 3.09 & 0.05 & -3.9 \\
\hline Initial shell length (covariate) & 1 & 0.77 & 12.28 & $7 e-04$ & 0U1A, 0U2A vs. $2 \mathrm{U} 1 \mathrm{~A}, 2 \mathrm{U} 2 \mathrm{~A}$ & 18.33 & $6 e-05$ & -10.24 \\
\hline Sex & 1 & 0.2 & 3.23 & 0.1 & $1 \mathrm{U} 1 \mathrm{~A}, 1 \mathrm{U} 2 \mathrm{~A}$ vs. $2 \mathrm{U} 1 \mathrm{~A}, 2 \mathrm{U} 2 \mathrm{~A}$ & 7.14 & $9 e-03$ & -6.09 \\
\hline Residual & 88 & 0.06 & & & & & & \\
\hline Foot dry weight $[\operatorname{sqrt}(y)]$ & & & & & 0U2A vs. 1U1A & 1.44 & 0.24 & -1.24 \\
\hline C. rodgersii & 2 & 1.17 & 0.92 & 0.35 & 1U2A vs. 2U1A & 2.56 & 0.5 & -4.53 \\
\hline H. rubra & 1 & 1.88 & 1.3 & 0.3 & 0U1A vs. 0U2A & 15.55 & $1 \mathrm{e}-03$ & -18.67 \\
\hline C. rodgersii $\times H$. rubra & 2 & 7.34 & 6.1 & 0.01 & 0U1A, 0U2A vs. 1U1A,1U2A & 0.03 & 0.86 & -2 \\
\hline Initial shell length (covariate) & 1 & 22.63 & 17.72 & $6 e-05$ & 0U1A, 0U2A vs. 2U1A, 2U2A & 0.62 & 0.44 & -5.98 \\
\hline Residual & 89 & 1.27 & & & $1 \mathrm{U} 1 \mathrm{~A}, 1 \mathrm{U} 2 \mathrm{~A}$ vs. $2 \mathrm{U} 1 \mathrm{~A}, 2 \mathrm{U} 2 \mathrm{~A}$ & 0.45 & 0.51 & -3.32 \\
\hline \multicolumn{9}{|l|}{ Shell dry weight $[\log (y+0.0001)]$} \\
\hline C. rodgersii & 2 & 292 & 0.65 & 0.52 & & & & \\
\hline H. rubra & 1 & 35 & 0.08 & 0.79 & & & & \\
\hline C. rodgersii $\times H$. rubra & 2 & 133 & 0.3 & 0.75 & & & & \\
\hline Initial shell length (covariate) & 1 & 1139 & 2.51 & 0.12 & & & & \\
\hline Residual & 85 & 454 & & & & & & \\
\hline \multicolumn{5}{|c|}{ Stomach content dry weight $[\log (y+0.001)]$} & 0U2A vs. 1U1A & 10.71 & $3 e-03$ & -2.19 \\
\hline C. rodgersii & 2 & 1.87 & 32.75 & $3 e-11$ & $1 \mathrm{U} 2 \mathrm{~A}$ vs. $2 \mathrm{U} 1 \mathrm{~A}$ & 8.07 & $8 e-03$ & -1.37 \\
\hline H. rubra & 1 & 0.81 & 18.6 & $2 e-04$ & 0U1A vs. 0U2A & 15.04 & $4 e-04$ & -1.21 \\
\hline C. rodgersii $\times H$. rubra & 2 & 0.4 & 7.71 & $1 e-03$ & 0U1A, 0U2A vs. $1 \mathrm{U} 1 \mathrm{~A}, 1 \mathrm{U} 2 \mathrm{~A}$ & 60.58 & $7 e-11$ & -0.13 \\
\hline Initial shell length (covariate) & 1 & 0.4 & 5.47 & 0.02 & 0U1A, 0U2A vs. 2U1A, 2U2A & 22.16 & $2 e-06$ & -1.86 \\
\hline Residual & 85 & 0.06 & & & 1U1A,1U2A vs. 2U1A, 2U2A & 1.83 & 0.21 & -0.06 \\
\hline
\end{tabular}




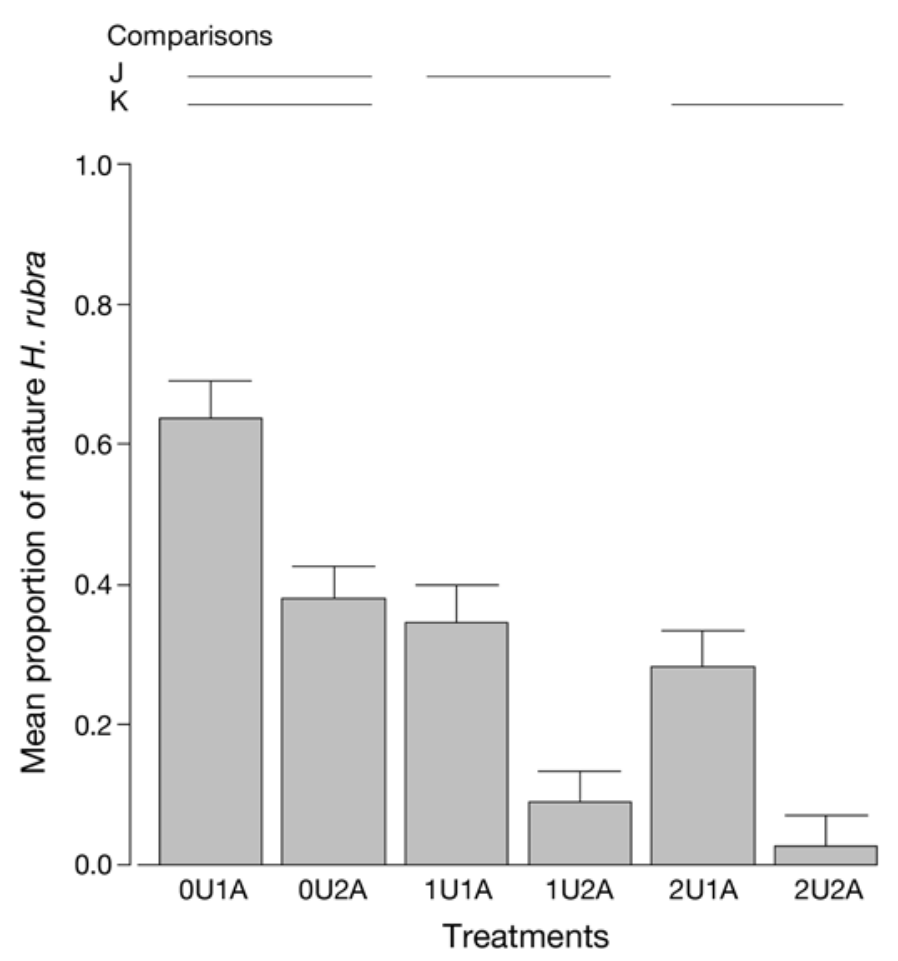

Fig. 3. Centrostephanus rodgersii and Haliotis rubra. Effects of intra- and interspecific competition on the proportion of mature $H$. rubra (see Table 4$)$. Data are means $( \pm \mathrm{SE})$ of $\mathrm{n}=3$. $0 \mathrm{U}, 1 \mathrm{U}$ and $2 \mathrm{U}: 0 \times, 1 \times$ and $2 \times$ ambient density $C$. rodgersii $1 \mathrm{~A}$ and $2 \mathrm{~A}$ : $1 \times$ and $2 \times$ ambient density $H$. rubra. Comparisons are-J: 0U1A, 0U2A versus $1 \mathrm{U} 1 \mathrm{~A}, 1 \mathrm{U} 2 \mathrm{~A}$; K: 0U1A，0U2A versus 2U1A, 2U2A. Connecting lines indicate significant differences between groups of treatment means
There were no detectable differences in the relative effects of intra- and interspecific competition on the dry weights of Haliotis rubra gonad and foot. In contrast, inter- rather than intraspecific competition accounted for declines in $H$. rubra total weight and in the weight of dry stomach contents.

\section{Effect of competition on gonad development}

There was no evidence that either intra- or interspecific competition influenced the proportion of Centrostephanus rodgersii that spawned (C. rodgersii, $Z=$ 2.09, df $=1, \mathrm{p}=0.99$; Haliotis rubra, $Z=0.75, \mathrm{p}=0.99$; $C$. rodgersii $\times H$. rubra, $Z=1.49$, $\mathrm{df}=2, \mathrm{p}=0.14$ ).

In contrast, inclusion of Centrostephanus rodgersii in enclosures at ambient or double ambient densities resulted in similar declines in the proportion of mature Haliotis rubra relative to controls without urchins (Fig. 3, Table 4). Differences in the relative effects of intra- and interspecific competition were not significant.

\section{Effect of competition on survivorship}

There was some mortality of Centrostephanus rodgersii (36.4\%) and Haliotis rubra (42.15\%) during the experiment (Figs. $4 \& 5$, Table 4), but no evidence that intra- or interspecific competition affected survivorship of $C$. rodgersii. In contrast, manipulation of C. rodgersii densities suggests that the presence of the

Table 4. Centrostephanus rodgersii and Haliotis rubra. Results of logistic regression and survival analysis testing effects of intraand interspecific competition on $H$. rubra gonad development and $C$. rodgersii and $H$. rubra survivorship through time. Significant $p$-values are in bold print: $p<0.05$ values are significant for the main analysis and $p<0.01$ values are significant for comparisons ( $\alpha$-adjusted using the method by Todd \& Keough 1994)

\begin{tabular}{|c|c|c|c|c|c|c|c|c|}
\hline Source of variation & df & $\begin{array}{c}\text { Deviance } \\
\text { residual }\end{array}$ & $\begin{array}{l}\text { Residual } \\
\text { deviance }\end{array}$ & $\mathrm{p}$ & Comparisons & $\begin{array}{l}\text { Residual } \\
\text { deviance }\end{array}$ & $\mathrm{p}$ & $\begin{array}{c}\text { Effect } \\
\text { size }\end{array}$ \\
\hline \multicolumn{9}{|l|}{ Logistic regression } \\
\hline \multicolumn{9}{|l|}{ H. rubra } \\
\hline Null & & & 123.28 & & 0U2A vs. 1U1A & 31.46 & 0.03 & -1.69 \\
\hline C. rodgersii & 1 & 15.28 & 106.72 & $4 e-05$ & $1 \mathrm{U} 2 \mathrm{~A}$ vs. $2 \mathrm{U} 1 \mathrm{~A}$ & 41.28 & 0.23 & 1.03 \\
\hline H. rubra & 2 & 1.29 & 122 & 0.26 & 0U1A vs. 0U2A & 32.68 & $2 e-03$ & -2.7 \\
\hline C. rodgersii $\times H$. rubra & 2 & 15.49 & 106.72 & $4 e-05$ & 0U1A, 0U2A vs. 1U1A, 1U2A & 81.92 & $5 e-02$ & -1.34 \\
\hline Initial shell length(covariate) & 1 & 0 & 106.72 & 0.97 & 0U1A, 0U2A vs. 2U1A, 2U2A & 66.12 & $1 e-03$ & -2.54 \\
\hline \multicolumn{9}{|l|}{$\underline{\text { Survival analysis }}$} \\
\hline \multicolumn{9}{|l|}{ C. rodgersii } \\
\hline Null & & & 1174.65 & & & & & \\
\hline C. rodgersii & 1 & 2.09 & 1172.56 & 0.35 & & & & \\
\hline H. rubra & 2 & 0.75 & 1171.81 & 0.39 & & & & \\
\hline C. rodgersii $\times H$. rubra & 2 & 3.58 & 1168.23 & 0.17 & & & & \\
\hline H. rubra & & & & & 0U2A vs. 1U1A & 256.24 & 0.1 & -0.37 \\
\hline Null & & & 1012.99 & & 1U2A vs. $2 \mathrm{U} 1 \mathrm{~A}$ & 556.24 & 0.01 & -0.67 \\
\hline C. rodgersii & 2 & 11.24 & 1001.71 & $3 e-03$ & 0U1A, 0U2A vs. $1 \mathrm{U} 1 \mathrm{~A}, 1 \mathrm{U} 2 \mathrm{~A}$ & 545.88 & 0.01 & -0.73 \\
\hline H. rubra & 1 & 4.65 & 1012.95 & 0.85 & 0U1A, 0U2A vs. 2U1A, 2U2A & 579.32 & $2 e-03$ & -0.82 \\
\hline C. rodgersii $\times H$. rubra & 2 & 0.03 & 997.06 & 0.1 & 1U1A,1U2A vs. 2U1A, 2U1A & 739.41 & 0.64 & -0.11 \\
\hline
\end{tabular}


urchin at ambient densities leads to a decrease in the survivorship of $H$. rubra. However, the effects of $C$. rodgersii on $H$. rubra survivorship at ambient and double ambient densities were similar.

\section{Effects of enclosures and grazing on algae}

There were no significant effects of enclosures on the cover of total algae $\left(F_{1,4}=0.46, \mathrm{p}=0.88\right)$ or on brown $\left(F_{1,4}=0.14, \mathrm{p}=0.12\right)$ and red components of the algal assemblage $\left(F_{1,4}=1, \mathrm{p}=0.99\right)$. There were no significant effects either of enclosures on the biomass of total $\left(F_{1,4}=0.01, \mathrm{p}=0.23\right)$ or brown $\left(F_{1,4}=1.05, \mathrm{p}=\right.$ $0.34)$ and red $\left(F_{1,4}=0.6, \mathrm{p}=0.77\right)$ algae.

Grazing by Haliotis rubra over 6 mo resulted in a slight but not significant decline in the standing biomass and cover of red algae. In contrast, additions of Centrostephanus rodgersii at ambient density or greater resulted in linear declines in the cover and standing biomass of total algae and of brown and red algae (Figs. 6 \& 7, Table 5).

\section{DISCUSSION}

One of the crucial questions in invasion biology is to quantify the nature, direction and results of interspecific competitive interactions for food between invasive and native species (Byers 2000). We examined competitive interactions between the invasive urchin Centrostephanus rodgersii and the commercially fished abalone Haliotis rubra. Previous studies have examined interactions between these 2 herbivores (Shepherd 1973, Andrew et al. 1998), but the present work is the first field study to experimentally test the effect of competition for food on C. rodgersii and H. rubra body condition, gonad development and survival, in intact algal beds. There was strong evidence for intra- and interspecific competitive interactions for food between $C$. rodgersii and $H$. rubra, prior to any destructive grazing by the urchin.

\section{Effects of intraspecific competition}

Intraspecific competition for food had marked effects on the body condition of Centrostephanus rodgersii and Haliotis rubra. Doubling the ambient density of conspecifics led to declines in the dry gonad weight of C. rodgersii, and the dry foot and stomach content weights of $H$. rubra within the 6 mo time frame of the experiment. Our results are likely to be representative of natural populations, because treatment densities were well within naturally occurring densities of

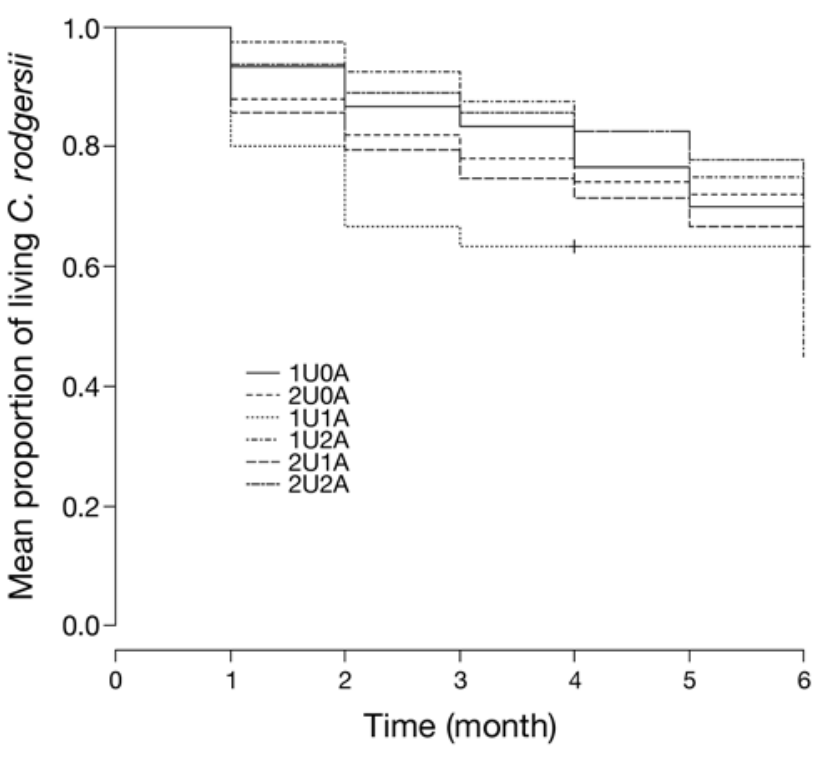

Fig. 4. Centrostephanus rodgersii and Haliotis rubra. Effects of intra- and interspecific competition on the proportion of living individuals through time (see Table 5). Data are means $( \pm \mathrm{SE})$ of $\mathrm{n}=3.1 \mathrm{U}$ and $2 \mathrm{U}: 1 \times$ and $2 \times$ ambient density $C$. rodgersii; $0 \mathrm{~A}, 1 \mathrm{~A}$ and $2 \mathrm{~A}$ : $0 \times, 1 \times$ and $2 \times$ ambient density H. rubra

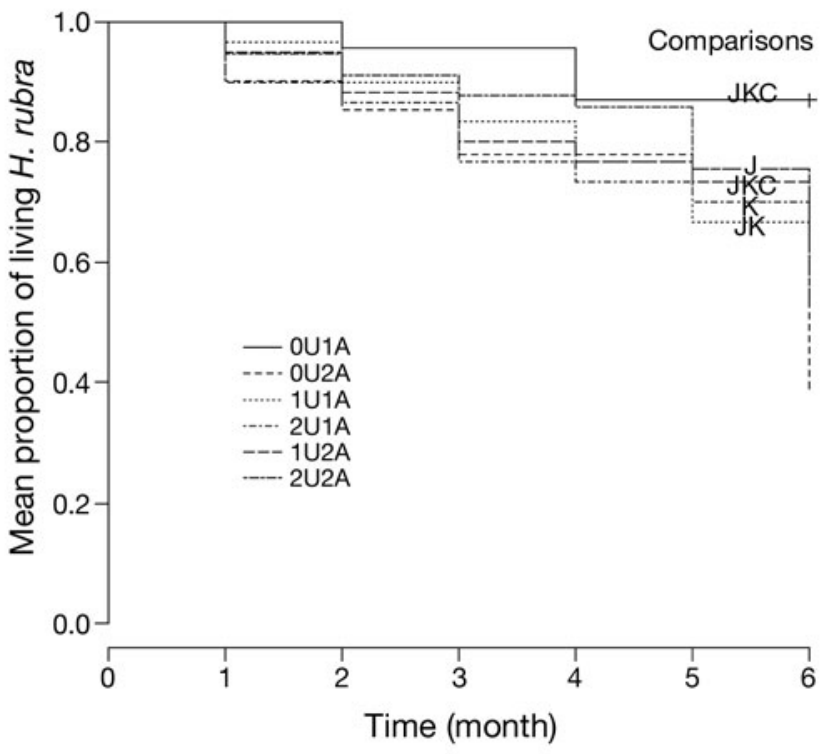

Fig. 5. Centrostephanus rodgersii and Haliotis rubra. Effects of intra- and interspecific competition the proportion of living of $H$. rubra through time (see Table 4$)$. Data are means $( \pm$ SE) of $\mathrm{n}=3.0 \mathrm{U}, 1 \mathrm{U}$ and $2 \mathrm{U}: 0 \times, 1 \times$ and $2 \times$ ambient density $C$. rodgersii; $1 \mathrm{~A}$ and $2 \mathrm{~A}: 1 \times$ and $2 \times$ ambient density $H$. rubra. Comparisons are $-\mathrm{C}$ : 0U2A versus $1 \mathrm{U}_{1} \mathrm{~A}_{i} \mathrm{~J}$ : 0U1A, 0U2A versus 1U1A, 1A2U; K: 0U1A, 0U2A versus 2U1A, 2U2A. Letters indicate significant differences between treatment means and between groups of treatment means 
a Total algae

a Comparisons

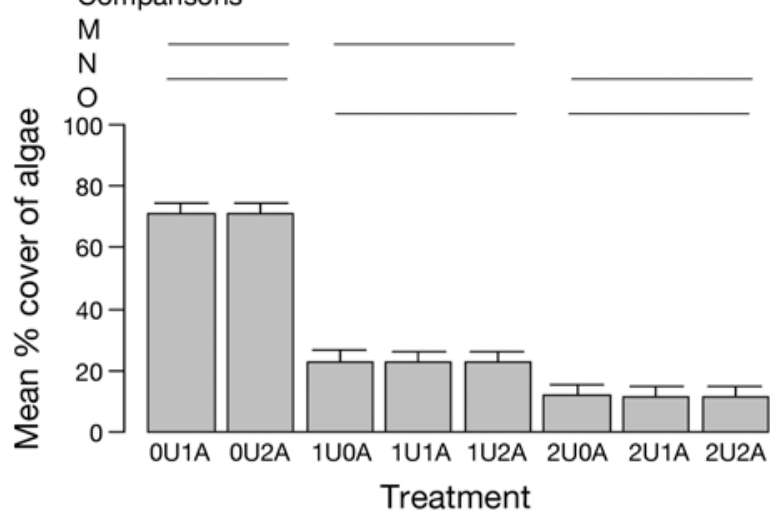

C Red

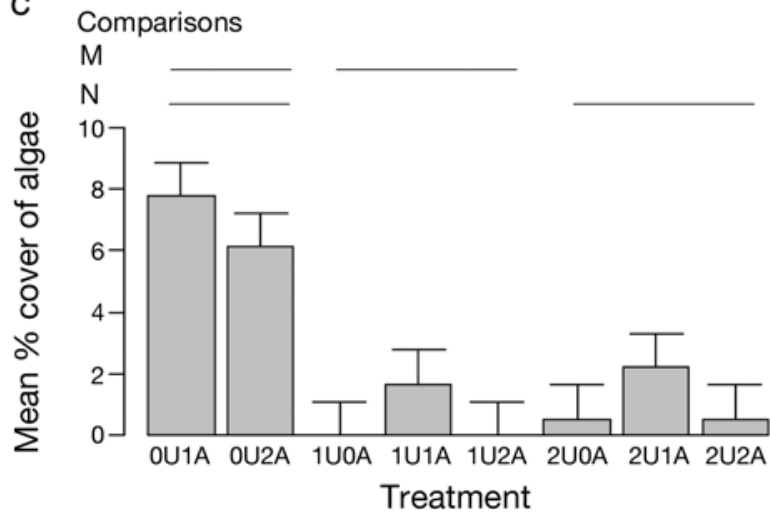

a Total algae

Comparisons

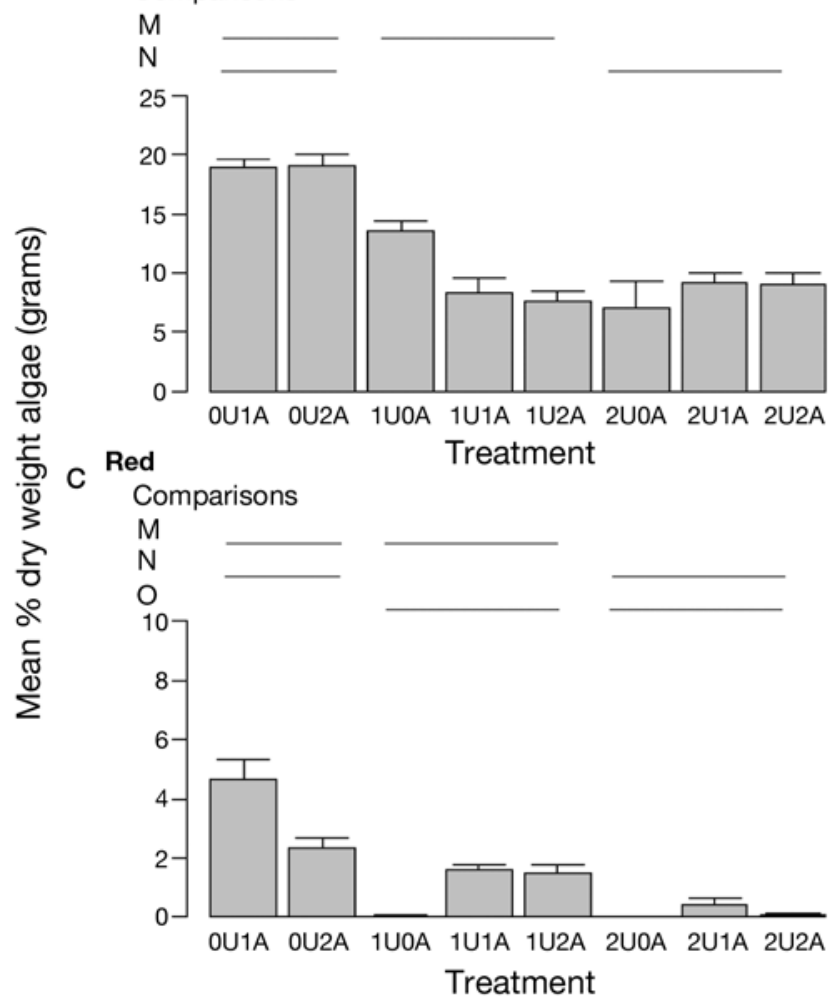

\section{b Brown}

Comparisons

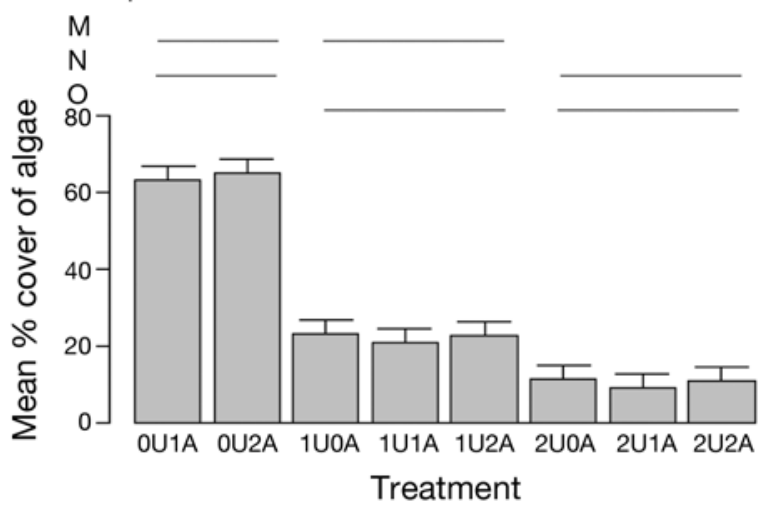

Fig. 6. Centrostephanus rodgersii and Haliotis rubra. Effects of $C$. rodgersii on the cover of (a) total algae, (b) brown and (c) red algae (see Table 5). Data are means $( \pm \mathrm{SE})$ of $\mathrm{n}=3.0 \mathrm{U}$, $1 \mathrm{U}$ and $2 \mathrm{U}$ : $0 \times, 1 \times$ and $2 \times$ ambient density $C$. rodgersii; $0 \mathrm{~A}, 1 \mathrm{~A}$ and $2 \mathrm{~A}: 0 \times, 1 \times$ and $2 \times$ ambient density $H$. rubra. Comparisons are $-\mathrm{M}$ : 0U1A, 0U2A versus $1 \mathrm{U} 0 \mathrm{~A}, 1 \mathrm{U} 1 \mathrm{~A}, 1 \mathrm{U} 2 \mathrm{~A}$; N: 0U1A, 0U2A versus $2 \mathrm{U} 0 \mathrm{~A}, 2 \mathrm{U} 1 \mathrm{~A}, 2 \mathrm{U} 2 \mathrm{~A}$; O: $1 \mathrm{U} 0 \mathrm{~A}, 1 \mathrm{U} 1 \mathrm{~A}, 1 \mathrm{U} 2 \mathrm{~A}$ versus $2 \mathrm{U} 0 \mathrm{~A}, 2 \mathrm{U} 1 \mathrm{~A}, 2 \mathrm{U} 2 \mathrm{~A}$. Connecting lines indicate significant differences between groups of treatment means

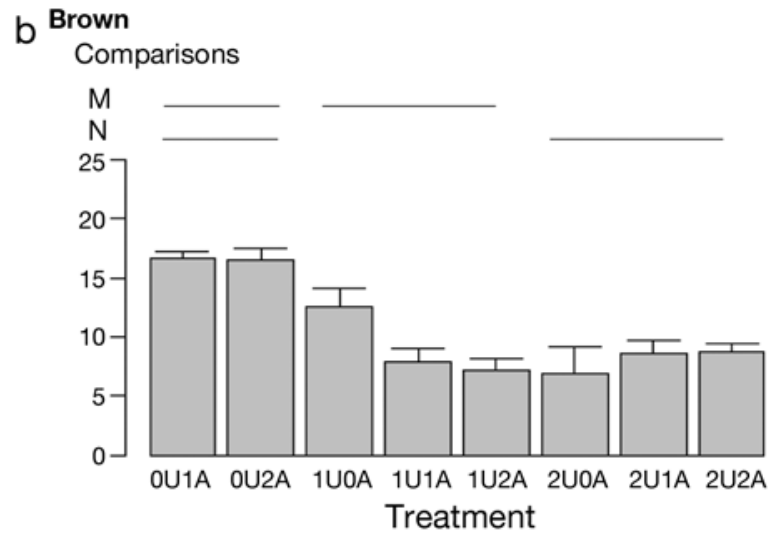

Fig. 7. Centrostephanus rodgersii and Haliotis rubra. Effects of $C$. rodgersii on the mean dry weight (g) of (a) total algae, (b) brown and (c) red algae (see Table 5). Data are means $( \pm \mathrm{SE})$ of $\mathrm{n}=3.0 \mathrm{U}, 1 \mathrm{U}$ and $2 \mathrm{U}: 0 \times, 1 \times$ and $2 \times$ ambient density C. rodgersii; $0 \mathrm{~A}, 1 \mathrm{~A}$, and $2 \mathrm{~A}: 0 \times, 1 \times$ and $2 \times$ ambient density H. rubra. Comparisons are-M: 0U1A, 0U2A versus $1 \mathrm{U} 0 \mathrm{~A}$, 1U1A, 1U2A; N: 0U1A, 0U2A versus 2U0A, 2U1A, 2U2A; O: 1U0A, 1U1A, 1U2A versus 2U0A, 2U1A, 2U2A. Connecting lines indicate significant differences between groups of treatment means 
$C$. rodgersii and $H$. rubra in Tasmania, and in some areas their densities can greatly exceed those tested (Johnson et al. 2005). Furthermore and notably, there was no evidence that the body condition and gonad development of either species was influenced by enclosures.

Our findings are consistent with other research results on the effect of intraspecific competition in urchins, including Centrostephanus rodgersii (Blount 2004). Individuals co-existing at high densities in barrens are often smaller (test width and height) and have smaller gonads (wet weight), than those at sites with fewer urchins (Byrne et al. 1998), and in individuals in intact algal beds (Ling et al. 2008). Blount (2004) found that, in barrens, C. rodgersii in low-density treatments (33 and 66\% removals) had larger gonads relative to body size and increased growth (estimated from jaw pieces) and fecundity (number of eggs) compared to individuals in high-density treatments ( $0 \%$ removal). It seems clear that an increased density of urchins has deleterious effects on the body condition and repro- ductive output of individual $C$. rodgersii in the wild; however, the impacts are intensified in a barrens habitat compared with in intact algal beds (Ling et al. 2008).

\section{Effects of interspecific competition}

We tested the role of interspecific competition for food in explaining the establishment of Centrostephanus rodgersii and the eventual exclusion of Haliotis rubra from intact algal beds. There was clear evidence of interspecific competition, but the nature of the interaction was asymmetrical. C. rodgersii negatively affects the body condition and survival of $H$. rubra, but there was no discernable effect of abalone on urchins. These results suggest that removal of $H$. rubra through intensive fishing is unlikely to be important in facilitating the establishment of $C$. rodgersii on the east coast of Tasmania.

Table 5. Centrostephanus rodgersii and Haliotis rubra. Results of ANOVAs testing the effects of C. rodgersii and H. rubra on the cover and dry weight $(\mathrm{g})$ of total algae, brown and red algae. Significant $\mathrm{p}$-values are in bold print: $\mathrm{p}<0.05$ values are significant for the main analysis and $p<0.016$ values are significant for comparisons ( $\alpha$-adjusted using the method by Todd \& Keough 1994 )

\begin{tabular}{|c|c|c|c|c|c|c|c|c|}
\hline Source of variation & $\mathrm{df}$ & MS & $F$ & $\mathrm{p}$ & Comparisons & $F$ & $\mathrm{p} E$ & Effect size \\
\hline \multicolumn{9}{|l|}{ Cover } \\
\hline \multicolumn{9}{|l|}{$\overline{\text { Total algae }}$} \\
\hline C. rodgersii & 2 & 6947.2 & 92.63 & $2 e-09$ & 0U1A, 0U2A vs. 1U0A,1U1A,1U2A & 102.73 & $2 e-07$ & $7-49.72$ \\
\hline H. rubra & 2 & 5.6 & 0.08 & 0.93 & 0U1A, 0U2A vs. 2U0A, 2U1A, 2U2A & 190.73 & $4 e-09$ & $9-60.84$ \\
\hline C. rodgersii $\times H$. rubra & 3 & 59.3 & 0.79 & 0.52 & 1U0A,1U1A,1U2A vs. 2U0A, 2U1A, 2U2A & 11.04 & $5 e-03$ & $3-11.1$ \\
\hline Residual & 16 & 75.0 & & & & & & \\
\hline \multicolumn{9}{|l|}{ Brown algae } \\
\hline C. rodgersii & 2 & 5442.4 & 64.5 & $2 e-08$ & 0U1A, 0U2A vs. 1U0A, 1U1A, 1U2A & 67.14 & $2 e-06$ & $6-42.78$ \\
\hline H. rubra & 2 & 11.8 & 0.14 & 0.87 & 0U1A, 0U2A vs. 2U0A, 2U1A, 2U2A & 142.63 & $2 e-08$ & $8-54.45$ \\
\hline C. rodgersii $\times H$. rubra & 3 & 58.3 & 0.69 & 0.57 & 1U0A,1U1A, 1U2A vs. 2U0A, 2U1A, 2U2A & 10.57 & $5 e-03$ & $3-11.68$ \\
\hline Residual & 16 & 84.4 & & & & & & \\
\hline \multicolumn{9}{|c|}{ Red algae $[\log (y+0.001)]$} \\
\hline C. rodgersii & 2 & 100.7 & 19.34 & $5 e-05$ & 0U1A, 0U2A vs. 1U0A,1U1A,1U2A & 37.79 & $3 e-05$ & $5-7.92$ \\
\hline H. rubra & 2 & 6.25 & 1.2 & 0.33 & 0U1A, 0U2A vs. 2U0A, 2U1A, 2U2A & 25.01 & $3 e-03$ & $3-7$ \\
\hline C. rodgersii $\times H$. rubra & 3 & 0.93 & 0.18 & 0.91 & $1 \mathrm{U} 0 \mathrm{~A}, 1 \mathrm{U} 1 \mathrm{~A}, 1 \mathrm{U} 2 \mathrm{~A}$ vs. $2 \mathrm{U} 0 \mathrm{~A}, 2 \mathrm{U} 1 \mathrm{~A}, 2 \mathrm{U} 2 \mathrm{~A}$ & 0.37 & 0.56 & -.95 \\
\hline Residual & 16 & 5.21 & & & & & & \\
\hline \multicolumn{9}{|l|}{ Dry weight } \\
\hline Total algae $[\operatorname{sqrt}(y)]$ & & & & & 0U1A, 0U2A vs. 1U0A, 1U1A, 1U2A & 45.78 & $6 e-06$ & $6-1.28$ \\
\hline C. rodgersii & 2 & 5.47 & 42.74 & $3 e-07$ & 0U1A, 0U2A vs. 2U0A, 2U1A, 2U2A & 72.88 & $3 e-07$ & $7-1.51$ \\
\hline H. rubra & 2 & 0.09 & 0.68 & 0.53 & 1U0A,1U1A,1U2A vs. 2U0A, 2U1A, 2U2A & 1 & 0.35 & -0.23 \\
\hline C. rodgersii $\times H$. rubra & 3 & 0.43 & 3.34 & 0.04 & 1U0A, 2U0A vs. 0U1A, 1U1A, 1U2A & 0.01 & 0.93 & -0.04 \\
\hline Residual & 16 & 0.13 & & & $1 \mathrm{U} 0 \mathrm{~A}, 2 \mathrm{U} 0 \mathrm{~A}$ vs. $0 \mathrm{U} 2 \mathrm{~A}, 1 \mathrm{U} 2 \mathrm{~A}, 2 \mathrm{U} 2 \mathrm{~A}$ & 0.04 & 0.86 & -0.08 \\
\hline \multicolumn{9}{|l|}{ Brown algae $[\operatorname{sqrt}(y)]$} \\
\hline C. rodgersii & 2 & 4.31 & 31.1 & $2 e-06$ & 0U1A, 0U2A vs. 1U0A, 1U1A, 1U2A & 36.3 & $2 e-05$ & $5-6.03$ \\
\hline H. rubra & 2 & 0.14 & 1 & 0.4 & 0U1A, 0U2A vs. 2U0A, 2U1A, 2U2A & 54.56 & $2 e-06$ & $6-1.34$ \\
\hline C. rodgersii $\times H$. rubra & 3 & 0.36 & 2.57 & 0.08 & 1U0A,1U1A,1U2A vs. 2U0A, 2U1A, 2U2A & 0.74 & 0.4 & -0.2 \\
\hline Residual & 16 & 0.14 & & & & & & \\
\hline \multicolumn{9}{|l|}{ Red algae } \\
\hline C. rodgersii & 2 & 8.84 & 18.51 & $6 e-05$ & 0U1A, 0U2A vs. 1U0A,1U1A,1U2A & 16.85 & $1 e-03$ & $3-2.45$ \\
\hline H. rubra & 2 & 0.07 & 0.14 & 0.88 & 0U1A, 0U2A vs. $2 \mathrm{U} 0 \mathrm{~A}, 2 \mathrm{U} 1 \mathrm{~A}, 2 \mathrm{U} 2 \mathrm{~A}$ & 43 & $2 e-05$ & $5-3.34$ \\
\hline C. rodgersii $\times H$. rubra & 3 & 0.21 & 0.44 & 0.78 & 1U0A,1U1A, 1U2A vs. 2U0A, 2U1A, 2U2A & 9.6 & $7 e-03$ & $3-0.88$ \\
\hline Residual & 16 & 0.48 & & & & & & \\
\hline
\end{tabular}


Our findings are similar to those of the only other published study on interspecific competition for food between urchins and abalone (Tegner \& Levin 1982). Inclusion of Strongylocentotus franciscanus in tanks had a negative effect on the total weight of Haliotis rufescens relative to tanks without urchins. Contrary to our study, Tegner \& Levin (1982) also demonstrated that $H$. rufescens had a negative impact on increments in $S$. franciscanus test width and total weight. However, the importance of competition for food between these 2 herbivores in the wild is questionable, as there are substantial problems in extrapolating the results from tanks to the wild. Tegner \& Levin (1982) also had only 1 replicate tank for all treatments, their animals were weighed monthly, and the high variability in weight could have been influenced by handling stress (Ragg et al. 2000). Further testing is required to ascertain the nature of effects of interspecific competition for food on the growth of $S$. franciscanus and $H$. rufescens in the wild.

\section{Relative effects of intra- and interspecific competition}

The design allowed us to separate the relative effects of intra- and interspecific competition. Their relative strengths are critical in assessing whether interspecific competition has an important impact on the distribution and abundance of native and invasive herbivores (Byers 2000). If intraspecific competition is stronger than interspecific competition, then coexistence can occur (Berman \& Carlton 1991, Byers 2000), but, if the reverse situation exists, the inferior competitor may be excluded. The relative effects of competition differed between Centrostephanus rodgersii and Haliotis rubra.

Intra- but not interspecific competition resulted in declines in Centrostephanus rodgersii dry gonad weight. However, increases in urchin and abalone densities had no effect on C. rodgersii total weight, or the dry weight of the lantern, stomach contents, or test and spines combined, or the proportion of individuals that spawned or survived. This differential could be explained by the adaptations of urchins to food limitations. An increase in urchin density results in declines in the availability of preferred and total food, which could lead to an increase in food processing times and result in declines in dry gonad weight (Tegner \& Levin 1982, Andrew 1989). Overall the evidence suggests that neither intra- nor interspecific competition has an important influence on $C$. rodgersii abundances in intact algal beds within the 6 mo time frame of our experiment. Further evidence comes from Ling et al. (2008), who demonstrated that high urchin densities had very little impact on $C$. rodgersii reproductive capacity or total weight in intact algal beds.
For Haliotis rubra, the relative effects of intra- and interspecific competition varied depending on the response variables measured. The effects of intra- and interspecific competition on the dry weights of gonad and foot and on the proportion of mature abalone were similar. In contrast, inter- but not intraspecific competition led to declines in $H$. rubra in total weight, dry weight of stomach contents and survival of abalone. These results could be explained by the differences in $H$. rubra and C. rodgersii feeding preferences. An increase in abalone densities resulted in declines in the availability of preferred food and declines in H. rubra reproductive capacity, while the addition of $C$. rodgersii to the system reduces the total availability of food, with negative effects on abalone body condition and survival. These results suggest that inter- rather than intraspecific competition is likely to have stronger effects on $H$. rubra.

\section{Effects on algae}

For competition to affect the abundance and distribution of species, a common resource must be limiting (Byers 2000). Centrostephanus rodgersii and Haliotis rubra share similar food resources in that they both feed on algae; however, these 2 herbivores have very different impacts on this resource. Increases in the density of $C$. rodgersii resulted in declines in the cover and dry weight of total algae, as well as brown and red algae considered separately. In contrast, the presence of $H$. rubra resulted in a slight but not significant decline in the cover and standing biomass of red algae relative to the effect of $C$. rodgersii. This differential reflects differences in their feeding habits and morphology.

Centrostephanus rodgersii is a generalist herbivore that grazes intensively on a range of algae and sessile invertebrates (Andrew et al. 1998). In contrast, Haliotis rubra is a specialist herbivore that preferentially traps and/or grazes on red algae with low intensity (Shepherd 1973). Our results demonstrated that $C$. rodgersii has a broader range of dietary preferences and a higher feeding rate than $H$. rubra.

In the enclosures, Centrostephanus rodgersii monopolized the algae resources to a greater extent than Haliotis rubra, and the impacts of the urchins on the abalone could have been linked to food shortages. $C$. rodgersii were less affected by such food shortage, because urchins are more efficient at converting low, medium and high densities of algal resources to body weight and are better adapted to survive low abundances of food than abalone (Tegner \& Levin 1982, Andrew 1989). These results suggest that the impacts of $C$. rodgersii on $H$. rubra could be linked to exploitative competition for food. 


\section{Impacts of Centrostephanus rodgersii on Haliotis rubra}

The incursion of $C$. rodgersii has a negative impact on the abundance, distribution and condition of individual $H$. rubra on the east coast of Tasmania. In previous research, we demonstrated that introducing C. rodgersii to intact algal beds causes abalone to emigrate from open plots and to seek shelter in cryptic microhabitats (Strain \& Johnson unpubl. data). The present results suggest that, as $C$. rodgersii establishes at a site, the body condition and survival of $H$. rubra will decline. Clearly then, the establishment of C. rodgersii in intact algal beds has important and negative consequences for the abalone fishery prior to any onset of destructive grazing.

A crucial issue in competitive interactions between invasive and native herbivores is whether one species will be excluded. Our results demonstrate an asymmetrical interaction in which Centrostephanus rodgersii has a clear impact on Haliotis rubra, but the abalone has no detectable effect on the sea urchin. Nevertheless, it would appear that $C$. rodgersii and $H$. rubra can co-exist in intact algal beds (Andrew \& Underwood 1992). It is possible that $C$. rodgersii exclusion of $H$. rubra takes a long time, or that co-existence of $C$. rodgersii and $H$. rubra is linked to an inability of the urchin to inhabit shallow waters (approximately $<5 \mathrm{~m}$ ) at high population densities, where abalone occur in considerable abundance (Johnson et al. 2005), or to an incomplete overlap in food resource utilisation.

\section{CONCLUSIONS}

Overall, the invader (Centrostephanus rodgersii) is the superior competitor in interactions with the native herbivore Haliotis rubra. There was no evidence to suggest that $H$. rubra had a similar negative effect on $C$. rodgersii. These results are consistent with other studies on the effects of interspecific competition between native and invasive herbivores, in which the great majority show that the invasive species is the superior competitor in interactions with native herbivores (Berman \& Carlton 1991, Carlton 1992, Byers 2000, Bohn \& Amundsen 2001, Bachelet et al. 2004, Steffani \& Branch 2005). Our results strongly suggest that superior competitive ability, which is most often likely in a generalist consumer, is an important factor in predicting the impact of invasive herbivores on marine ecosystems (Carlton 1992, Byers 2000).

Acknowledgements. We thank those who assisted with fieldwork, particularly Michael Davis and Richard Holmes. E.M.A.S. was supported by the UTas-CSIRO Joint PhD Program in Quantitative Marine Research. The present study was part of a PhD thesis supported by a UTAS Postgraduate
Award. The research was supported by TAFI and TAC grants awarded to C.R.J. The manuscript was improved by comments from 4 anonymous reviewers and the editor John Lawrence.

\section{LITERATURE CITED}

Andrew NL (1989) Contrasting ecological implications of food limitation in sea urchins and herbivorous gastropods. Mar Ecol Prog Ser 51:189-193

Andrew NL, Underwood AJ (1992) Associations and abundance of urchins and abalone on shallow subtidal reefs in southern New South Wales. Mar Freshw Res 43: 1547-1559

Andrew NL, Worthington DG, Brett PA, Bentley N R, Chick C, Blount C (1998) Interactions between the abalone fishery and urchins in New South Wales. Final Report Series No. 12, NSW fisheries, Sydney

Bachelet G, Simon-Bouhet B, Desclaux C, Garcia-Meunier P and others (2004) Invasion of the eastern Bay of Biscay by the nassariid gastropod Cyclope neritea: origin and effects on resident fauna. Mar Ecol Prog Ser 276:147-159

Baltz DM, Moyle PB (1993) Invasion resistance to introduced species by a native assemblage of California stream fishes. Ecol Appl 3:246-255

Berman J, Carlton JT (1991) Marine invasion processes: interactions between native and introduced marsh snails. J Exp Mar Biol Ecol 150:267-281

Blount C (2004) Density dependent aspects of the sea urchin Centrostephanus rodgersii. $\mathrm{PhD}$ thesis, University of Sydney

Bohn T, Amundsen PA (2001) The competitive edge of an invading specialist. Ecology 82:2150-2163

Byers JE (2000) Competition between two estuarine snails: implications for invasions of exotic species. Ecology 81: 1225-1239

Byrne M, Andrew NL, Worthington DG, Brett PA (1998) Reproduction in the diadematoid sea urchin Centrostephanus rogersii in contrasting habitats along the coast of New South Wales, Australia. Mar Biol 132:305-318

Carlton JT (1992) Introduced marine and estuarine mollusks of North America: an end-of-the-20th-century perspective. J Shellfish Res 11:489-505

Day E, Branch GM (2000) Evidence for a positive relationship between juvenile abalone Haliotis midae and the urchin Parechinus angulosus in the south western Cape, South Africa. S Afr J Mar Sci 22:145-156

Edgar GJ (1984) General features of the ecology and biogeography of Tasmanian subtidal rocky shore communities. Pap Proc R Soc Tasman 118:173-186

Edgar GJ (1997) Australian marine life. Reed Books, Kew, Victoria

Huchette SMH, Koh CS, Day RW (2003) The effects of density on the behaviour and growth of juvenile blacklip abalone (Haliotis rubra). Aquaculture 11:411-428

Jensen GC, McDonald SP, Armstrong DA (2002) East meets west: competitive interactions between green crab Carcinus maenas, and native and introduced shore crab Hemigrapusus spp. Mar Ecol Prog Ser 225:251-262

Johnson C, Ling S, Ross J, Scoresby S, Miller K (2005) Establishment of the long-spined urchin (Centrostephanus rodgersii) in Tasmania: first assessment of the potential threats to fisheries. Final report, Fisheries Research Development Corporation, Hobart, Tasmania

> Ling DS, Johnson CR, Fruscher S, King CK (2008) Reproductive potential of a marine ecosystem engineer at the edge of a newly expanded range. Glob Change Biol 14:907-915 
Naylor R, Gerring P (2001) Interaction between pauna and kina. Water Atmos 9:16-17

Pederson HG, Johnson CR (2006) Predation of the urchin Heliocidaris erythrogramma by rock lobsters (Jasus edwardii) in no-take marine reserves. J Exp Mar Biol Ecol 336:120-134

Ragg NLC, Taylor HH, Behrens J (2000) Stress and weight loss associated with handling in the blackfoot abalone, Haliotis iris. J Shellfish Res 19:528-529

Rogers-Bennett L, Hearse JS (2001) Indirect benefits of marine protected areas for juvenile abalone. Conserv Biol 15:642-647

Shepherd SA (1973) Competition between urchins and

Editorial responsibility: John Lawrence,

Tampa, Florida, USA abalone. Aust Fish 4:4-7

Steffani CN, Branch G (2005) Mechanisms and consequences of competition between and alien mussel, Mytilus galloprovincialis, and an indigenous limpet, Scutellastra argenvillei. J Exp Mar Biol Ecol 317:127-142

Tegner MJ, Levin LL (1982) Do urchins and abalone compete in the California kelp communities? In: Lawrence J (ed) International echinoderms conference. A.A.Balkema, Rotterdam, p 265-271

Todd CD, Keough MJ (1994) Larval settlement in hard substratum epifaunal assemblages: a manipulative field study of the effects of substratum filming and the presence of incumbents. J Exp Mar Biol Ecol 181:159-187

Submitted: June 23, 2008; Accepted: November 5, 2008

Proofs received from author(s): February 6, 2009 